\title{
Generalisability of trials of home blood pressure monitoring; a comparison of two UK primary care trials
}

\author{
Sally M Kerry ${ }^{1 *}$, Hugh S Markus ${ }^{2}$, Teck K Khong ${ }^{3}$, Pippa Oakeshott ${ }^{4}$ \\ From Clinical Trials Methodology Conference 2011 \\ Bristol, UK. 4-5 October 2011
}

\section{Objective}

Blood pressure (BP) monitors are widely available and easy for patients to use. Systematic reviews [1-3] show that home monitoring of BP improves BP control but there is significant heterogeneity between studies, and meta regression has only been able to explain part of the heterogeneity, with concomitant interventions being a possible factor.

Most evidence comes from trials of patients who have poorly controlled blood pressure at baseline, although not usually explicitly stated in trial or review title. However many hypertensive patients using home monitors may have BP below the recommended target

Two large recent UK RCTs $[4,5]$ have been carried out with very different inclusion criteria and interventions. The objective is to compare the main findings of these trials and assess how far difference between the trial populations might explain the apparent difference in the efficacy of the intervention between the two trials.

\section{Methods}

In 2007-9, 381 hypertensive stroke patients were recruited from stroke services in London, and randomly allocated, at home, to either home BP monitoring $(n=187)$, with ongoing telephone support from a nurse, or usual care $(n=194)$. Patients were included without any restriction on baseline BP [4].

The TASMINH trial [5] randomised 527 primary care patients with baseline BP between 140/90 and 200/100, to a self management program $(n=263)$ or control $(\mathrm{n}=264)$. The program involved two training sessions for

'Blizard Institute, Barts and The London School of Medicine and Dentistry, Queen Mary University of London, London, E1 2AB, UK

Full list of author information is available at the end of the article patients, so that they could increase their medications when necessary, without consulting the GP.

The primary endpoint for both trials was change in mean systolic BP between baseline and 12 months follow up after adjusting for baseline BP. A post hoc subgroup analysis of those patients in the stroke study with baseline BP between 140/90 and 200/100 was carried out for comparison.

\section{Results}

Follow up rates for survivors were over $90 \%$ in both trials.

Intervention effect in the TASMINH trial was 5.4(2.4 to 8.5$) ; \mathrm{n}=480$, and was $0.3(-3.6$ to 4.80$)$ in the stroke trial; $\mathrm{n}=337$.

Of 1650 patients assessed for eligibility in the TASMINH trial, 916 (55\%) had BP less than 140/90 and 48 had BP above 200/100. These patients were excluded prior to randomisation.

$133(40 \%)$ patients in the stroke trial had baseline BP between 140/90 and 200/100; the intervention effect in this group was $5.9(-0.3$ to 12.0$) ; \mathrm{p}=0.02$ for interaction.

\section{Conclusions}

Whether or not patients with controlled hypertension, who comprise more than half the hypertensive population, are included, may explain the difference in effect size between these 2 trials.

\section{Acknowledgements}

The trial of home blood pressure monitoring in stroke patients was funded by The Stroke Association TSA 2006/05 and recruitment to the study was supported by the English National Institute of Health Research Clinical Stroke Research Network

(C) 2011 Kerry et al; licensee BioMed Central Ltd. This is an open access article distributed under the terms of the Creative Commons 


\section{Author details}

'Blizard Institute, Barts and The London School of Medicine and Dentistry, Queen Mary University of London, London, E1 2AB, UK. ${ }^{2}$ Stroke and Dementia Research Group, St George's, University of London, London, SW17 ORE, UK. 'Basic Medical Sciences, St George's, University of London, London, SW17 ORE, UK. "Population Health Sciences and Education, St George's, University of London, London, SW17 ORE, UK.

Published: 13 December 2011

\section{References}

1. Bray EP, Holder R, Mant J, McManus RJ: Does self-monitoring reduce blood pressure? Meta-analysis with meta-regression of randomized controlled trials. Annals of Medicine 2010, 42(5):371-86.

2. Cappuccio FP, Kerry SM, Forbes L, Donald A: Blood pressure control by home monitoring: meta-analysis of randomised trials. BMJ 2004, 329:145-151.

3. Agarwal R, Bills JE, Hecht TJW, Light RP: Role of home blood pressure monitoring in overcoming therapeutic inertia and improving hypertension control: a systematic review and meta-analysis. Hypertension 2011, 57:29-38.

4. Kerry S, Markus H, Khong T, Doshi R, Conroy R, Oakeshott P: Community based trial of home blood pressure monitoring with nurse-led telephone supports in patients with stroke or transient ischaemic attack recently discharged from hospital. Trials 2008, 9:15.

5. McManus RJ, Mant J, Bray EP, Holder R, Jones MI, Greenfield S, Kaambwa B, Banting M, Bryan S, Little P, Williams B, Hobbs FDR: Telemonitoring and self-management in the control of hypertension (TASMINH2): a randomised controlled trial. Lancet 2010, 376:163-72.

doi:10.1186/1745-6215-12-S1-A99

Cite this article as: Kerry et al:: Generalisability of trials of home blood pressure monitoring; a comparison of two UK primary care trials. Trials 2011 12(Suppl 1):A99.

\section{Submit your next manuscript to BioMed Central} and take full advantage of:

- Convenient online submission

- Thorough peer review

- No space constraints or color figure charges

- Immediate publication on acceptance

- Inclusion in PubMed, CAS, Scopus and Google Scholar

- Research which is freely available for redistribution

Submit your manuscript at www.biomedcentral.com/submit
Biomed Central 